\title{
The olfactory system of the tammar wallaby is developed at birth and directs the neonate to its mother's pouch odours
}

\author{
Nanette Y Schneider, Terrence P Fletcher, Geoff Shaw and Marilyn B Renfree \\ Department of Zoology, The University of Melbourne, Melbourne, Victoria 3010, Australia \\ Correspondence should be addressed to M B Renfree; Email: m.renfree@zoology.unimelb.edu.au
}

\begin{abstract}
In kangaroos and wallabies at birth the highly altricial newborn young climbs unassisted from the urogenital opening to the teat. Negative geotropism is important for the initial climb to the pouch opening, but nothing is known of the signals that then direct the neonate downwards to the teat. Here we show that the newborn tammar wallaby (Macropus eugenii) has the olfactory apparatus to detect smell. Both the main olfactory system and vomeronasal organ (VNO) are developed at the time of birth. Receptor cells of the main olfactory epithelium immunopositive for $\mathrm{G}_{\mathrm{o} \alpha}$-protein project to the three layered main olfactory bulb (MOB). The receptor epithelium of the VNO contains G-protein immunopositive cells and has olfactory knob-like structures. The VNO is connected to an area between the two MOBs. Next, using a functional test, we show that neonates can respond to odours from their mother's pouch. When neonatal young are presented with a choice of a pouch-odour-soaked swab or a saline swab, they choose the swab with their mother's pouch secretions significantly more often $(P<0.05)$ than the saline swab. We conclude that both olfactory systems are capable of receiving odour signals at birth, a function that must be a critical adaptation for the survival of an altricial marsupial neonate such as the tammar for its journey to the pouch.
\end{abstract}

Reproduction (2009) 138 849-857

\section{Introduction}

Mammalian neonates need to be able to locate the teats to survive and grow and there is evidence that eutherian neonates rely on olfactory cues to locate them (Teicher \& Blass 1977, Pedersen \& Blass 1982, Stickrod et al. 1982, Hudson \& Distel 1983). The main chemical cues involved in guiding the young can be detected by smell or taste and are apparently learned during fetal development through the presence of odour or taste in the amniotic fluid (Pedersen \& Blass 1982, Stickrod et al. 1982). The major detecting site for these signals was thought to be the vomeronasal organ (VNO) of the accessory olfactory system (Graves \& Duvall 1983). The $\mathrm{VNO}$ is present at some point in the development or life history of every extant tetrapod species examined so far and is regarded as a homologous feature throughout tetrapod evolution. However, the main olfactory system also senses pheromones. The mother-young aggregation pheromone in wild rabbits (Mykytowycz \& Ward 1971) that guides the young rabbit to its mother's teat (Schaal et al. 2003) activates a specific area in the dorso-medial region of the main olfactory bulb (MOB; Teicher et al. 1980). Furthermore, rabbits with surgical ablation of the VNO can still locate the teats (Hudson \& Distel 1986). Odour also guides newborn rats to their mothers' teats (Teicher \& Blass 1977, Hudson \& Distel 1983).
The detection of these pheromones depends on specific receptors in the olfactory epithelia (Kovach \& Kling 1967, Tirindelli et al. 1998). There are two large families of G-protein-linked receptors that are expressed only in mature receptor cells of the VNO (Berghard \& Buck 1996, Krieger et al. 1999). The V1R or V2R family receptors are unrelated to their counterparts in the main olfactory epithelium (MOE), suggesting that many active ligands are likely to act via the $\mathrm{VNO}$ receptors in addition to those in the main olfactory system (Halpern \& Martinez-Marcos 2003). Thus, there is considerable overlap in function between the two systems.

The tammar wallaby, Macropus eugenii, delivers a highly altricial young after a 26.5 days pregnancy (Tyndale-Biscoe \& Renfree 1987). When giving birth, kangaroos and wallabies usually sit with their tail passed forward between their legs (Tyndale-Biscoe \& Renfree 1987, Renfree et al. 1989). The neonate crawls unassisted upwards on its mother's abdomen to reach the pouch entrance where it then switches direction and crawls downwards to the teat. There it will attach permanently for the next several weeks or months. Exactly how the newborn young manages this impressive feat of navigation is yet to be determined. The young placed on the fur while their mothers are inclined at different angles invariably climb upwards, suggesting that the young use gravity, at least initially (Cannon et al. 1976). Most 
marsupials have a functional vestibular system at birth complete with otoliths, cilia and microcilia (Hughes \& Hall 1984, Gemmell \& Nelson 1988, Gemmell \& Rose 1989, McCluskey et al. 2008). However, since the neonates need to turn through $\sim 180^{\circ}$ to reach the teats within the pouch, there must be other signals that guide the young to the teats. There are olfactory sensory cells within the olfactory epithelium at birth so it is likely that olfaction plays a role in directing the young once it is near the pouch entrance (McCrady 1938, Hill \& Hill 1955, Gemmell \& Nelson 1988, Lin et al. 1988, Hughes et al. 1989, Renfree et al. 1989).

Once in the pouch, Merkel mechanoreceptors cells in the skin around the mouth in all marsupial neonates examined (Hughes \& Hall 1984, Jones \& Munger 1985, Gemmell et al. 1988, Gemmell \& Rose 1989) may be important for the attachment to the teat and they may even function to stop the drive to climb upwards (Hughes et al. 1989). The tammar MOE primordium is visible as a thickened layer three days before birth and is connected via nerves to a pre-olfactory bulb condensation at birth (Hughes et al. 1989). There is also a VNO which has a tall columnar epithelium and is innervated by a branch of the nervus terminalis (Hughes et al. 1989). However, whether these organs are functional is not yet known, although young were not attracted to a cotton bud swab from the mother's pouch when smeared on a human forearm (Hughes et al. 1989). The neonatal tammar is developmentally at a stage equivalent to a 9 week human fetus or a 17-day-old rabbit fetus (Tyndale-Biscoe \& Renfree 1987), and recent study of the neuronal connections of the olfactory epithelia in the tammar at birth suggested that the olfactory system is not sufficiently mature to be involved in guiding the neonate to the pouch and teat (Ashwell et al. 2008).

Despite its altriciality, the tammar is therefore equipped with at least rudimentary senses of balance, touch and smell, but direct evidence for the use of smell is lacking. Here we describe the structure of the olfactory systems and their function around birth in the neonatal tammar wallaby. We investigated the presence of $\mathrm{G}_{\mathrm{o} \alpha^{-}}$ protein and tested whether the neonatal wallaby uses smell to orientate itself towards and down into the pouch.

\section{Results}

\section{The main olfactory system}

The overall structure of the main olfactory system, based on gross anatomy, and light and electron microscopic observations was similar in the fetus $24 \mathrm{~h}$ before birth and in the young in the neonatal pouch (data from neonates shown in Figs 1 and 2). The nostrils were open to the nasal cavities and the respiratory epithelium that lined the nasal cavity consisted of a single cell layer in which goblet cells were embedded. They were especially aggregated at the rostral end of the nasal
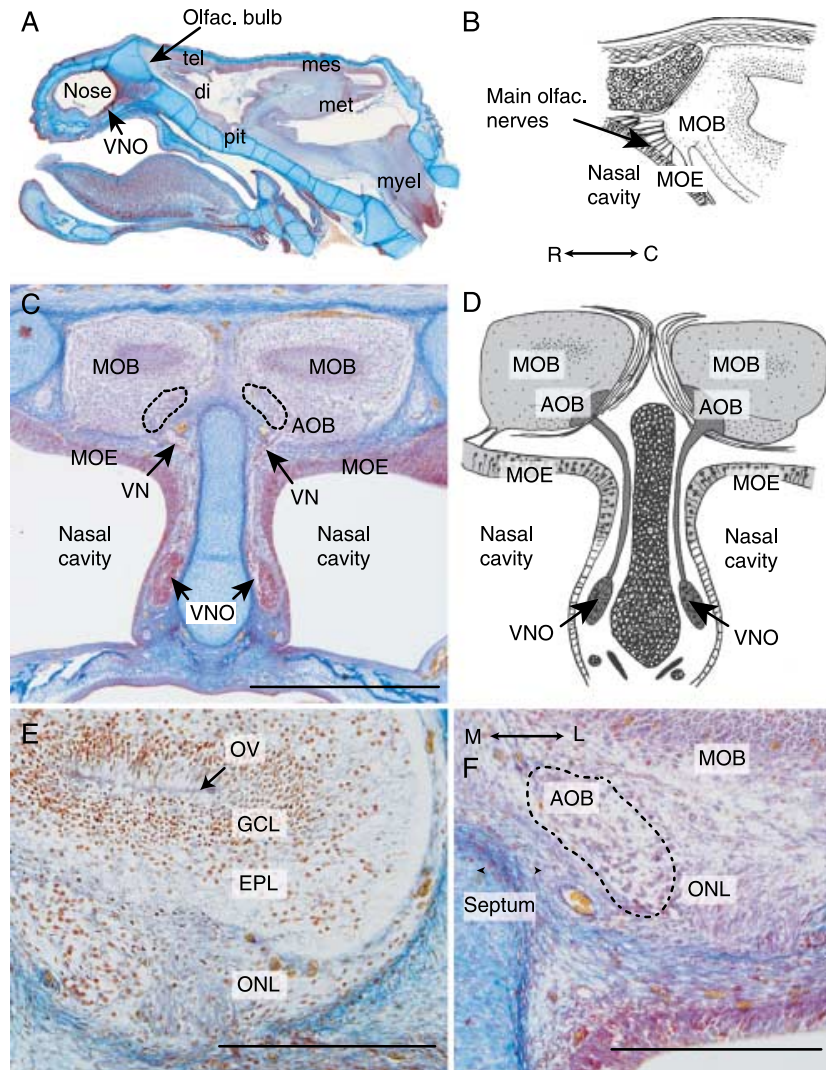

Figure 1 Olfactory bulbs and nasal cavity in the neonate tammar. (A) A sagittal section through the whole head of a neonate revealing the VNO at the base of the septum. di, diencephalon; mes, mesencephalon; met, metencephalon; myel, myelencephalon; tel, telencephalon; pit, pituitary. (B) Nerves are projecting from the main olfactory epithelium (MOE) to the olfactory bulb. R, rostral; C, caudal. (C) A coronal section of the head of a neonate tammar shows the vomeronasal organs (VNO) located medial to the nasal septum with the vomeronasal nerves (VN). Vomeronasal nerves lead along the nasal septum to the accessory olfactory bulb (AOB) dorsomedial to the main olfactory bulb (MOB; scale $500 \mu \mathrm{m}$ ). (D) A diagram of structures seen in C. (E) The neonate main olfactory bulb has an olfactory ventricle (OV, arrow) and three cell layers are visible: $\mathrm{ONL}$, olfactory nerve layer; $\mathrm{EPL}$, external plexiform layer; GCL, granular cell layer (scale $200 \mu \mathrm{m}$ ). (F) The AOB lies ventral from the MOB and shows only one cell layer (scale $200 \mu \mathrm{m}$ ).

cavity near the entrances of the naso-palatine ducts (NPDs) and the VNOs in the respiratory epithelium. Cilia covered the cell surfaces and goblet cells were lesselectron dense than the surrounding epithelial cells and had mucous droplets in their cell bodies. The goblet cells were stained with periodic acid-Schiff's (PAS) and Alcian blue $(A B)$ positive and the PAS staining was not altered through diastase treatment (data not shown).

The MOE lined the roof of the nasal cavity, starting rostral in the area of the entrance to the VNO. The epithelial height increased towards the caudal end of the nasal cavity reaching maximum height in the area where the VNO blindly ended. There were folds of the nasal cavity roof surface in the fetus and neonate (Fig. 3) that will form the ethmoturbinates in the adult. 

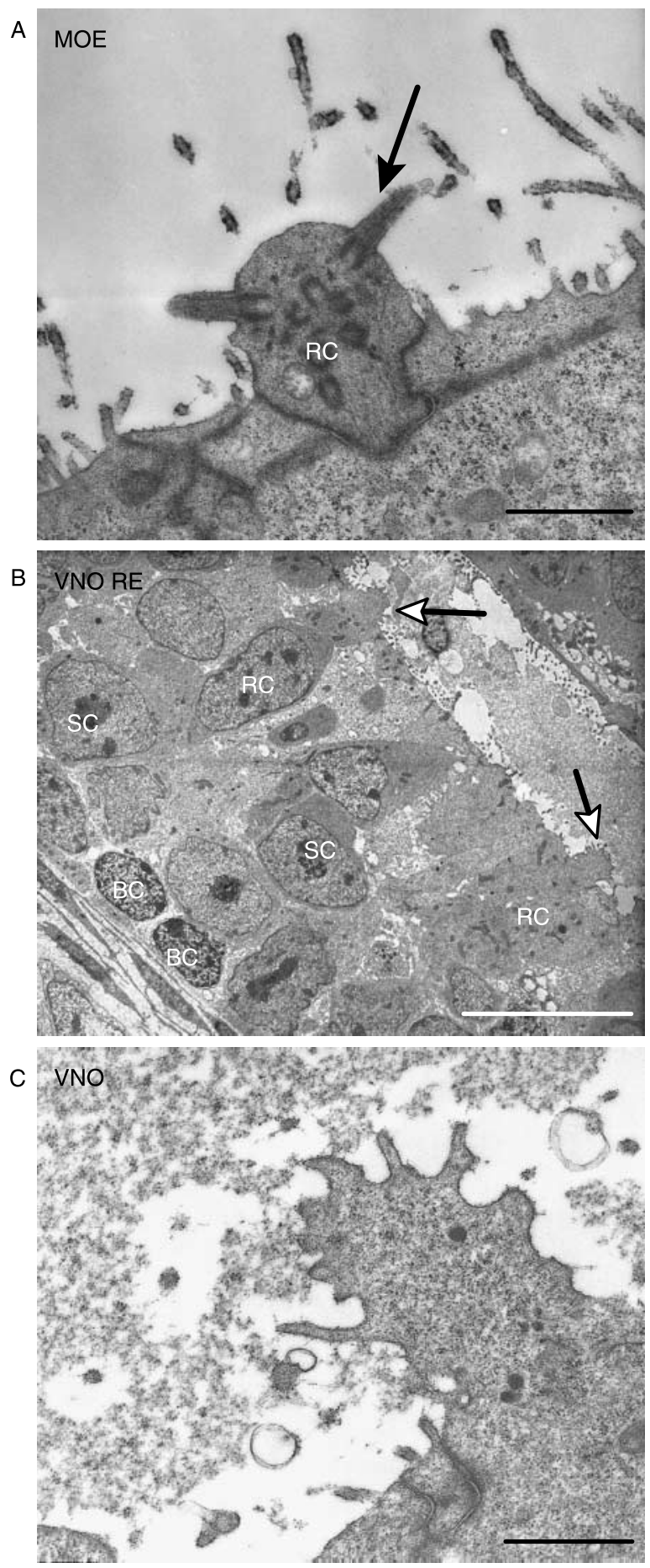

Figure 2 Electron micrographs of the main olfactory epithelium and sensory cells of the VNO of the neonate tammar. (A) The olfactory knobs on the main olfactory epithelium are covered by cilia (arrow). Microvilli are found on the supporting cells (scale $1 \mu \mathrm{m}$ ). (B) Three types of cells can be distinguished in the $\mathrm{VNO}$ receptor epithelium: basal cells $(\mathrm{BC})$ with small electron dense nuclei located at the base of the septum, receptor cells $(\mathrm{RC})$ with olfactory knob-like structures (arrows) on their surface which protrude into the VNO lumen and supporting cells (SC; scale $10 \mu \mathrm{m}$ ). (C) Olfactory knob-like structures found in the VNO receptor epithelium are covered with microvilli (scale $1 \mu \mathrm{m}$ ).
The MOE was a high pseudostratified columnar epithelium (Fig. 1C) readily distinguishable from the simple columnar respiratory epithelium. There was some positive PAS staining in the MOE and respiratory epithelium in the fetus. This disappeared or became less intense after diastase treatment. There was also some light $A B$ positive staining of the receptor epithelial surface. In the neonate, there was some $A B$ positive staining on the surface of the respiratory epithelium near the base of the nasal septum (not shown).

There were nerve bundles in the lamina propria underlining the $\mathrm{MOE}$, of which some connected the MOE with the MOB (Fig. 1B). $\mathrm{G}_{\mathrm{o} \alpha}$-protein was detected in cells throughout the MOE (Fig. 3A) and in the MOB (Fig. 3B and C). Western blots for $\mathrm{G}_{\alpha \alpha}$-protein from mouse forebrain and tammar olfactory bulb and VNO gave a single band of the expected size at around $39 \mathrm{kDa}$ (Fig. 4A). The cytoplasmic staining was found in the cell soma and in the dendrite projecting to the epithelial surface. The nerve bundles underlying the receptor epithelium were also darkly stained (Fig. 3A). There was no staining from IgG or negative controls (Fig. 4B).

The MOE was covered with microvilli and some cells also had cilia (Fig. 2A). Two types of cells were distinguishable in the MOE. One type of cell formed a bottleneck near the epithelial surface and ended with a knob-like structure that protruded into the nasal cavity (Fig. 2A). These protrusions looked like olfactory knobs and are presumably the receptor cells (Garrosa et al. 1998). Elongated mitochondria were very prominent in the receptor cells near the olfactory knob. The second type of cells had neither cilia on their surface nor any knob-like structure, but did have microvilli on their surface. These second type of cells were the supporting cells as previously described (Erhardt \& Meinel 1979). Both cell types had large nucleoli or heterochromatin accumulations in their nuclei. There were up to four nucleoli visible in each nucleus. The epithelium was underlined by the basement membrane which was visible as a thin line under the epithelium. The lamina propria lay underneath the basement membrane which included blood vessels, nerve bundles and connective tissue.

The MOB and the lamina propria were separated by connective tissue. The $\mathrm{MOB}$ had three distinguishable layers in the fetus. The external layer was the olfactory nerve layer, with the external plexiform layer between it and the granular cell layer (Fig. 1E). The layers of the MOB were even more evident in the newborn. However, it was not clear if the stratum glomerulorum was present as no glomeruli were observed.

\section{The accessory olfactory system}

The VNO of the fetus was well developed and indistinguishable from the neonate (Hudson \& Distel 1983). The VNO length was $0.625 \pm 0.071 \mathrm{~mm}$ within a total head length of $7.2 \pm 0.17 \mathrm{~mm}$, similar to the ratio 


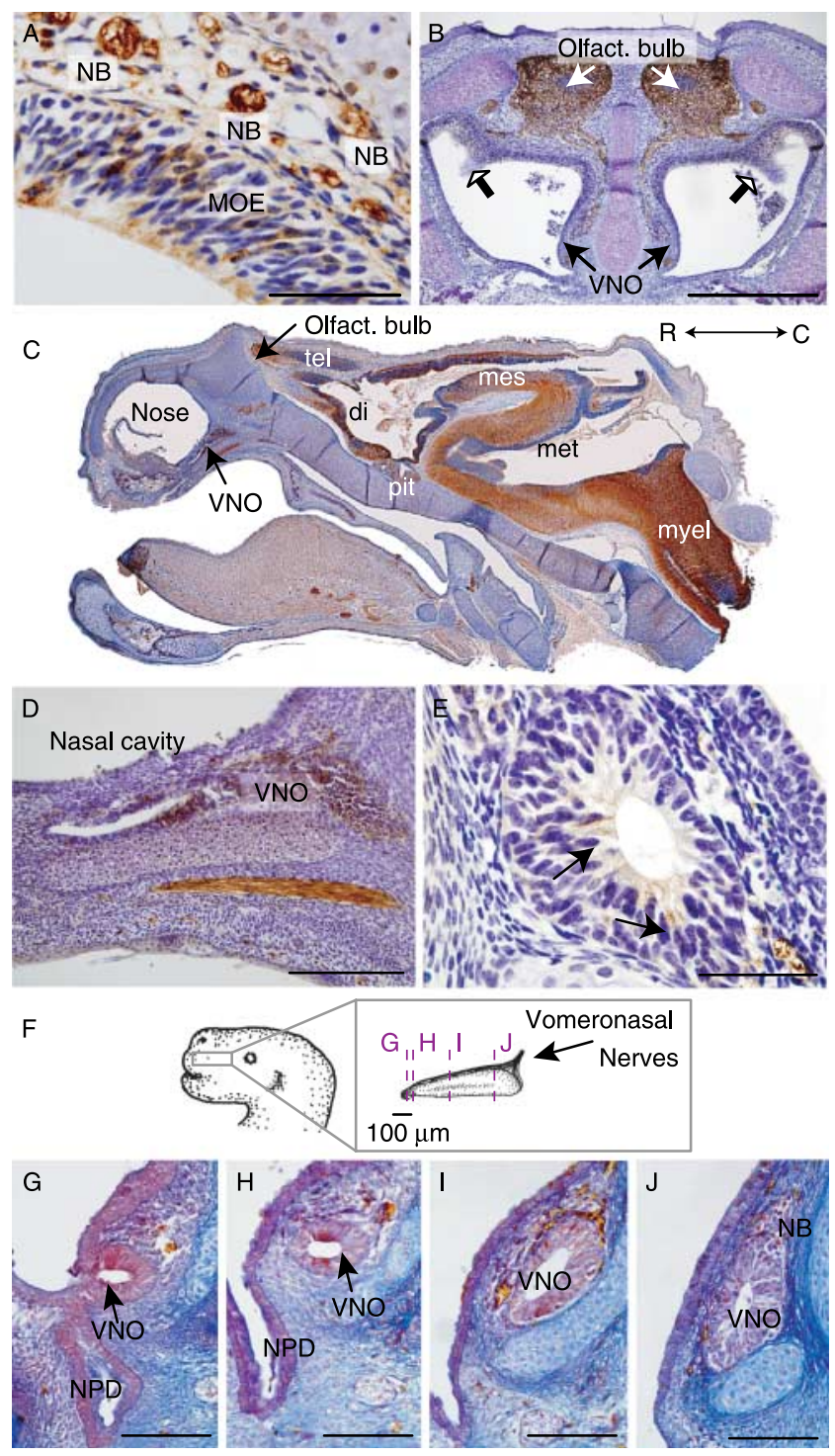

Figure $3 \mathrm{G}_{\mathrm{o} \alpha}$ protein expression in the brain, $\mathrm{MOB}$ and $\mathrm{VNO}$ of the neonate tammar. (A) $\mathrm{G}_{\mathrm{o} \alpha}$ immunopositive staining is found in the MOE and nerve bundles (NB) underlining the epithelium (scale $50 \mu \mathrm{m})$. (B) A coronal section through the caudal region of the nasal cavities in the MOB show strong $\mathrm{G}_{\mathrm{o} \alpha}$-positive staining in the olfactory nerves and vomeronasal nerves (scale $500 \mu \mathrm{m}$ ). Ethmoturbinates (thick arrows) are visible. (C) A sagittal section through the head of a neonate that the developing brain, the VNO, trigeminal nerve and elements of the tongue were strongly $\mathrm{G}_{\mathrm{o} \alpha}$ immunopositive. di, diencephalon; mes, mesencephalon; met, metencephalon; myel, myelencephalon; tel, telencephalon; pit, pituitary. (D) The close-up of the sagittal section through the VNO shows many stained cells. (E) $\mathrm{G}_{\mathrm{o} \alpha}$ positive stained cells (arrows) are found in the receptor epithelium of the VNO (scale $50 \mu \mathrm{m}$ ). Sections A-E are counterstained with haematoxylin. (G-J) Coronal sections through the neonate's vomeronasal organ (VNO) from rostral to caudal as indicated in F. The nasopalatine duct (NPD) and VNO open into the nasal cavity $(G)$. In J nerve bundles (NB) are visible leaving the VNO (Sections G-J stained with Mallory's Triple stain; scale for all $100 \mu \mathrm{m})$. of the $\mathrm{VNO}$ length to head length of the newborn. The VNO opened to the nasal cavity more rostrally than the entrance of the NPD. The NPDs were already open and their entrances lay under the wing-like structures of the prominent papilla incisiva. In the most rostral region of the VNO the lumen was crescent shaped with the long axis in the horizontal plane. The long axis of the lumen rotated from the horizontal to the vertical plane towards its caudal end (Fig. 3F-J). The lumen of the tubelike organ increased in size towards the posterior end. The height of both receptor and non-receptor epithelium were similar. The receptor epithelium was pseudostratified columnar, while the non-receptor epithelium was simple columnar. No vomeronasal glands could be observed in the fetus or neonate and only small blood vessels accompanied the VNO. Some PAS and AB-positive staining was found in the VNO lumen in day 25 fetus. The PAS staining was not altered through diastase digestion. No PAS or $A B$ positive staining could be observed in the VNO lumen of the pouch young at birth.

Structures similar to olfactory knob-like structures were found on the surface of the receptor epithelium of the $\mathrm{VNO}$ in two of the specimens (Fig. 2B and C). At the ultrastructural level, microvilli were found on both $\mathrm{VNO}$ epithelia while cilia were absent. Different types of cells were found in the receptor epithelium of the VNO. While basal cells could be identified by their position at the base of the epithelia, receptor or supporting cells could not be clearly distinguished from one another (Fig. 2B). No different cell types could be distinguished in the non-receptor epithelium which consisted of only one cell layer. Nucleoli or heterochromatin accumulations were found in the nuclei of all epithelial cells of the $\mathrm{VNO}$. There was immunoreactivity to $\mathrm{G}_{\mathrm{o} \alpha}$ protein in a few cells in the receptor epithelium of the VNO of the day 25 fetuses (Fig. 3D and E).

The distinct layers of receptor and supporting cell nuclei found in the adult (Salazar \& Sanchez Quinteiro 1998) were not observed in any of the pouch young. One big nerve bundle projected from the caudal end of each VNO along the septal cartilage to an area medial ventral between the two MOBs (Figs 1C, D and 3B). Only one cell type and no cell layers could be distinguished in this area (Fig. 1F).

\section{Behavioural test}

Neonates were placed on a tanned pelt where they had a choice to climb either towards a saline soaked swab or a swab with maternal pouch odour. All the neonates used in these studies were retrieved from their mother's pouch soon after birth, and all showed normal climbing behaviour when placed on the pelt (Fig. $5 \mathrm{~A}$ and $\mathrm{B}$ ). The neonates initially climbed uphill, but most veered away from the line straight up between the swabs (Fig. 5D). Eight pouch young turned away from the vertical path between the swabs, moving horizontally 
A

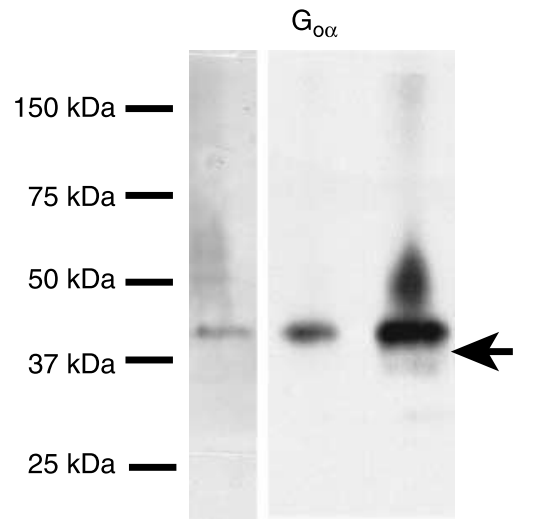

(1)

(2)

(3)

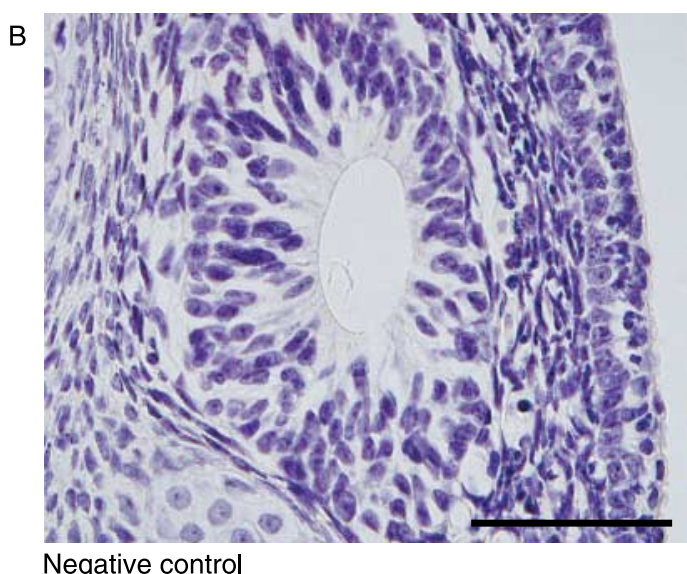

Figure 4 Controls for immunochemistry of $\mathrm{G}_{\mathrm{o} \alpha}$ protein. (A) There is a single band of $\mathrm{G}_{\mathrm{o} \alpha}$ at $39 \mathrm{kDa}$ for mouse brain (2) as well as tammar olfactory bulb (3) and VNO (1) on the western blot. (B) Negative control: the first antibody was omitted, and there is no immunostaining visible.

towards one of the swabs. Once near the mother's odour swab, six neonates turned to face down the incline (Fig. 5C). Some pouch young then climbed downwards on the pelt for a short distance after turning, an action that may help the neonate enter the pouch, had there been a pouch present on the section of pelt used. Other pouch young did not show such strong directional changes, but six 'burrowed' their heads into the pelt near the swab with their mother's odour and ceased to move their head constantly side to side as they did during the initial climb. In total, 15 out of 20 young chose the swab with their mother's odour while five chose the saline swab $(P=0.022)$. Three other neonates did not reach any of the swabs during the maximum $5 \mathrm{~min}$ of the trial because they became stuck in the pelt.

\section{Discussion}

Both the main olfactory and accessory olfactory systems of the tammar are well developed at birth and the receptors appear to be functional despite the fact that many other organ systems are poorly developed in the marsupial neonate.

\section{The main olfactory system of the neonate appears to be functional at birth}

Nearing birth, the nasal cavity has most of the structures that are present in the adult. The nasoturbinates have just started to form, and the respiratory epithelium consists of one cell layer. Even though mucous-secreting goblet cells are present before birth, there are no Bowman glands in any of the serial sections at birth, in contrast to the study by Hughes et al. (1989). In the adult, this structure increases the mucous-coated surface area of the nasal epithelia.

Although there are no ethmoturbinates on the day of birth, the MOE appears to be well developed enough to perceive an odour signal and has olfactory knobs on its surface as described in a number of marsupial newborns (Hill \& Hill 1955, Hughes et al. 1989, Gemmell \& Selwood 1994). The $\mathrm{G}_{\mathrm{o} \alpha}$-positive receptor cells are connected to the brain before birth, which would allow signal perception and transmission. The development of the MOE is similar to the E14 rat fetus (Farbman \& Menco 1986). Since electro-olfactograms recorded between E14 and E19 in the rat are of a similar magnitude to those of adults (Gesteland et al. 1982), it is likely that the tammar olfactory receptor cells are also capable of a physiological response. In the full term fetus, we found that the olfactory bulb is visibly divided into the olfactory nerve layer, the external plexiform layer and the granular cell layer similar to

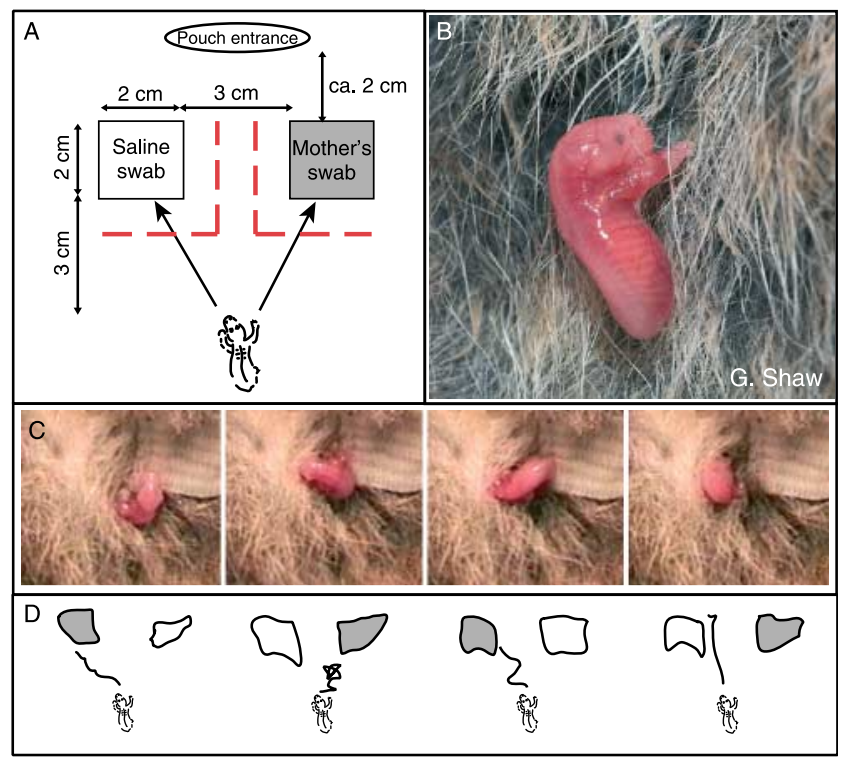

Figure 5 Behavioural test. (A) Y-maze set-up. (B) A neonate climbing towards the swabs. (C) Stills from video images of a neonate approaching a swab soaked with a wash from its mother's pouch (left panel), then turning and burrowing down into the pelt (top right panel). (D) Diagrams of paths taken by four different neonates traced on an acetate overlay of the video recordings. The dark figures indicate the swab from the mother's pouch; the white figures indicate the saline swab. 
that described in neonatal tammars (Ashwell et al. 2008). $\mathrm{G}_{\mathrm{o} \alpha}$ protein is present in the olfactory bulb and the rest of the brain, as seen in the brain of the adult tammar (N Y Schneider, T P Fletcher, G Shaw \& M B Renfree, unpublished data) and adult rat (Worley et al. 1986). This suggests that the brain even at this early stage of development is able to process incoming odour signals and that the main olfactory system in the tammar is functional at birth.

\section{The neonate has a well-developed accessory olfactory system with anatomical correlates of functional VNO neurones}

In contrast to newborn mice, hamsters and pigs, the $\mathrm{VNO}$ in the newborn tammar is open to the nasal cavity, so odours and pheromones could enter the lumen (Coppola et al. 1993, Wöhrmann-Repenning \& BarthMüller 1994, Taniguchi 2008). Since the mouth is permanently shut and filled with the teat after the neonate attaches to it, the direct opening of the VNO to the nasal cavity makes the perception of airborne chemical signals possible. The VNO lumen in the neonate rotates from a crescent shape in the horizontal plane adjacent to the entrance to the nasal cavity to a vertical plane at its caudal end. In the rat, the rotation of the VNO lumen is thought to be due to the development of the VNO from a groove in the septal wall (Estes 1972).

Mucous is produced to keep the epithelium lining the VNO lumen moist and to transport chemical cues along the length of the organ. The neonatal tammar has goblet cells around the entrance to the VNO lumen in the respiratory epithelium of the septum that could be a source of mucous for transport of pheromones into the $\mathrm{VNO}$ lumen. The blood vessels of the $\mathrm{VNO}$ are small, so it is unlikely that the newborn uses a pumping mechanism, as presumed in the adult tammar, to suck chemical cues into the lumen as suggested for rodents (Salazar \& Sanchez Quinteiro 1998, Schneider et al. 2008), nor could the pouch young use the venturi effect of air-flow in the NPD (Matsuoka et al. 2001) as the VNO is not yet connected to the former. The most probable way for chemical cues to enter the VNO would be by diffusion in mucous produced by the goblet cells in the nasal cavity entering the VNO lumen through capillary action. While the pumping mechanism in rodents is conducted by one blood sinus found at the medial lateral side of each VNO lumen (Salazar \& Sanchez Quinteiro 1998), contraction and expansion of the tammar VNO lumen could be achieved by the two big blood vessels on opposite sides of the VNO through pulsation of the blood or regulation of vascular tone (Schneider et al. 2008). The VNO of the neonate rat is similar that of the adult rat, but it lacks the bone capsule which surrounds the organ in the adult (Garrosa et al. 1992, 1998). A blood sinus is present in the neonate but whether it functions as part of a pumping mechanism at this age has not been investigated, but the lack of an enclosing bony capsule suggests that this pumping mechanism is not yet functional.

The receptor epithelium has olfactory knob-like structures before birth. These structures are part of vomeronasal receptor cells, as evidenced by the presence of G-protein that is coupled to V2R (Jia et al. 1997). Only mature receptor cells co-express this G-protein (Berghard \& Buck 1996, Krieger et al. 1999). $\mathrm{G}_{\mathrm{o} \alpha}$-immunoreactive cells are also found in the neonatal grey short-tailed opossum (Garrosa et al. 1992). Thus, the day 25 tammar fetus has mature receptor cells in the $\mathrm{VNO}$ that are presumably functional. There is also $\mathrm{G}_{\mathrm{o} \alpha}$ protein in the vomeronasal nerves that project to an area in the medial MOB.

The VNO of the neonatal tammar is at a similar stage of development as that of the rat at E16 (Coppola et al. 1993). Although the development of the tammar VNO is not as mature as in the neonatal rat, there are features that suggest that the organ is functional at birth. The area of the brain in which the vomeronasal nerves of the tammar fetus terminate has no obvious cell layers, but is $\mathrm{G}_{\mathrm{o} \alpha}$ positive indicating functional $\mathrm{VNO}$ neurones are present.

\section{Olfaction directs the young to the pouch}

Our results show that the newborn tammar is able to detect odours. The newborn tammar wallaby shows a clear preference for a direction that leads them to the swab with the odour signals from the mother's pouch. The pouch young that approached swabs with maternal odour showed distinct behavioural changes. Six changed direction, and started crawling down the incline as if they were entering the pouch. Six others burrowed into the fur. These data suggest that neonates approaching the pouch respond to pouch odours with a pattern of movement that facilitates their entry into the pouch. Whether altered skin or fur structure around the pouch entrance would have caused a similar behavioural change could not be determined as the pouch opening was not near any of the swabs and because the tanning process hardened the thin pouch skin.

Around the time of birth the mother licks the fur between the pouch and the urogenital opening. This acts to keep the climbing neonate moist and prevent them sticking to dry fur, as happened to three of the neonates in this experiment that became stuck on the fur and never reached either of the swabs. This saliva might potentially provide a taste-trail that could also assist the neonate's navigation. This could not be determined in this experiment because we used a tanned pelt so no maternal saliva was present. However, since the mother licks generally over the fur of the lower abdomen (Renfree et al. 1989), rather than licking a specific track towards the pouch, this seems unlikely to provide much directional assistance to the young. 
Ashwell et al. (2008) identified neural connections from the olfactory epithelium to the olfactory tubercle and basal forebrain but saw few connections past the olfactory bulb. They concluded that the olfactory system of newborn tammar is not sufficiently developed to play a role in guiding the young to the teat. However, this sensory system is required only for a simple switch in direction so minimal development may be sufficient. Our behavioural observations disagree with the conclusions of Ashwell et al. (2008) and show for the first time that the pouch young of the tammar wallaby is attracted to the odours from the mother's pouch (although our experiments did not assess the specificity of the behavioural response to odour). We conclude that both olfactory systems are capable of receiving odour signals at birth, a function that must be a critical adaptation for the survival of an altricial marsupial neonate such as the tammar for its journey to the pouch.

\section{Materials and Methods}

Tammar wallabies, M. eugenii, were maintained in open grassy yards in our breeding colony using standard husbandry conditions (Renfree \& Tyndale-Biscoe 1978). All experimental procedures and collection of tissues were approved by The University of Melbourne Animal Ethics Committees and conformed to Australian National Health and Medical Research Council guidelines (National Health and Medical Research Council 2004).

\section{Tissue preparation}

Heads of near term fetuses (day 25 of the 26.5 day gestation, $n=3)$, and neonates $(n=6)$ were collected for light microscopy and immunohistochemistry. Heads were fixed in $4 \%$ paraformaldehyde for one day, washed twice with PBS and stored in $70 \%$ ethanol. All samples were embedded in paraffin for serial section $(7 \mu \mathrm{m})$. Samples from the VNO and MOE $(n=3)$ of near term fetuses and neonates $(n=3)$ were collected for electron microscopy.

\section{Light microscopy}

Coronal sections were cut through the VNO of fetuses (day 25) and neonates ( $n=3$ at each stage). Every third slide was stained with Mallory's trichrome stain. Alternate sections were used for immunohistochemistry and the four sections of the caudal end of each VNO were stained with PAS, PAS diastase digestion technique and $\mathrm{AB}$. The length of the $\mathrm{VNO}$ was determined by counting the coronal sections on which the VNO was visible (including sections that were not stained) and multiplying by the section thickness. An additional three heads of newborn were cut in a sagittal plane.

\section{Transmission electron microscopy}

Samples were fixed in superfix at room temperature for $4 \mathrm{~h}$ or overnight at $4{ }^{\circ} \mathrm{C}$. The samples were washed three times for $10 \mathrm{~min}$ with $0.1 \mathrm{~mol} / \mathrm{l}$ cacodylate buffer at room temperature, placed in osmium tetroxide for $1-2 \mathrm{~h}\left(1 \% \mathrm{OsO}_{4}\right.$ in $0.2 \mathrm{~mol} / \mathrm{l}$ cacodylate buffer), washed with $0.1 \mathrm{~mol} / \mathrm{l}$ cacodylate buffer, dehydrated, embedded in resin (epon araldite) and cut with the ultramicrotome. Thick sections $(1 \mu \mathrm{m})$ were stained with $1 \%$ toluidene blue. Ultrathin sections $(90 \mathrm{~nm})$ were stained with uranyl acetate and Reynold's lead citrate and examined under the transmission electron microscope.

\section{Western blot}

Protein for western blot was extracted from snap frozen mouse forebrain, tammar olfactory bulb and tammar VNO using protease inhibitor cocktail (Calbiochem, Kilsyth, Australia; \# 535141) in RIPA buffer. Protein concentrations were measured with a spectrophotometer (NanoDrop ND-1000; NanoDrop, Wilmington, DE, USA). Samples were run on a $10 \%$ separating gel (SDS-PAGE) and blotted to a Hybond-p membrane (Amersham Biosciences). The membrane was blocked with 5\% skim milk in TTBS. The membrane pieces were incubated with a polyclonal rabbit antibody (Upstate, New York, NY, USA; \# 07-634) raised against purified native bovine $\mathrm{G}_{\mathrm{o} \alpha}$-protein in $5 \%$ skim milk/TTBS for $1 \mathrm{~h}$ in the dark on a roller. The membranes were washed three times for 5 min in TTBS and incubated with HRP-conjugated goat anti rabbit IgG (Santa Cruz, Santa Cruz, CA, USA; \# SC-2004) at $1 / 20000$ dilution for $30 \mathrm{~min}$. The membranes were washed $\times 3$ for $5 \mathrm{~min}$ in TTBS, exposed for $1 \mathrm{~min}$ to ECL (Santa Cruz) and exposed to a Hyperfilm (Amersham Biosciences) for $7 \mathrm{~min}$.

\section{$G_{o \alpha}$ immunohistochemistry}

Coronal sections from the middle of the VNO of the $\mathrm{d} 25$ fetuses and neonates were dehydrated and transferred into PBS. They were treated with $5 \%$ hydrogen peroxide for $5 \mathrm{~min}$, washed with PBS $(3 \times 5 \mathrm{~min})$, blocked with $10 \%$ goat serum and incubated overnight at $4{ }^{\circ} \mathrm{C}$ with $\mathrm{G}_{\mathrm{o} \alpha}$-antibody (Upstate, \# 07634 ) diluted $1 / 200$ plus $2 \%$ goat serum in $0.1 \%$ BSA in PBS. Control sections from each animal were incubated with rabbit IgG (Dako Australia, Kingsgrove, Australia; \# X0903), 1/200 dilution in $2 \%$ goat serum in $0.1 \%$ BSA or with $0.1 \%$ BSA in PBS, omitting the first antibody (negative control) at $4{ }^{\circ} \mathrm{C}$ overnight. The slides were washed $\times 3$ for 5 min with PBS and incubated with biotinylated goat anti-rabbit (Dako, \# E0432); diluted $1 / 500$ for $30 \mathrm{~min}$. After washing $\times 3$ for 5 min with PBS, the slides were incubated with Strept ABComplex/HRP kit (Dako, \# K0377) for $30 \mathrm{~min}$. A final washing step $(\times 3$ for each 5 min with PBS), preceded addition of DAB Chromogen (Dako, \# S3000) with $1 \mu \mathrm{H}_{2} \mathrm{O}_{2}$ per $1 \mathrm{ml}$ for 2-3 min. Haematoxylin was used as counterstain.

\section{Behavioural test}

In total, 23 neonates were used for behavioural observations. Ten neonates were recovered within 2 min post partum from females that were held in small pens and watched continuously for births (Renfree et al. 1989). The remaining neonates were recovered from females that were held in small grassy enclosures and checked every morning from day 25 of gestation. No behavioural differences were noted between 
these two sets of neonates. All pouch young used were able to navigate, since all had entered the pouch before recovery for use in this study. Pouch young were gently removed from the pouch and kept moist and warm. A $2 \mathrm{ml} 0.9 \%$ saline wash was collected from each mother's pouch by pipette after gently massaging it in the pouch. During this process the inside of the pouch was not touched. This mix of odour from the pouch and saline only contained water soluble components. This saline wash was placed in a sterile vial containing a $2 \times 2 \mathrm{~cm}$ cotton swab. A second cotton swab of the same size also in a sterile vial was soaked in $2 \mathrm{ml}$ of $0.9 \%$ saline. The samples in the vials including the swabs were warmed to hand temperature immediately before use by holding the vials in the palm of the gloved hand. The swabs were placed with clean forceps on the pelt using a template to ensure consistency in the set up. Each neonate was exposed to the swab from its own mother's pouch. The young were handled with bare hands as they are delicate and the rubber of gloves snags their skin. All pouch young handling and collection of odour samples were performed by the same person who had also tanned the pelt (see below) so that all young were equally exposed to this person's smell.

A piece of tanned tammar belly pelt, including the pouch opening, obtained from animals killed for other ethically approved experiments was placed inside an incubator $\left(34{ }^{\circ} \mathrm{C}\right)$ at an angle of $42.5-60.5^{\circ}$. The pelt was moistened with a spray of $0.9 \%$ saline. The two swabs, one with the mother's pouch odour and one with saline were placed on a horizontal line $3 \mathrm{~cm}$ apart (from edge of one swab to the edge of the other swab) on the pelt around $2 \mathrm{~cm}$ below the pouch entrance (Fig. 5A). Each pouch young was placed at the bottom of the ' $\mathrm{Y}$ ' with its head oriented in the direction of the pouch about $3 \mathrm{~cm}$ from the swabs (neonates normally have to climb about 5-8 cm from the urogenital opening to the pouch) and allowed to crawl for up to $5 \mathrm{~min}$ in up to three trials. Neonates that had not reached either swab within 5 min were were replaced at the base of the $Y$ and given repeated trials. The set up of the swabs were changed at random at each different trial of a young. Two pelts were used, one for placement of the swab soaked in clean saline on the left arm of the ' $Y$ ' and one for placement of the clean saline swab on the right arm of the $Y$, as cleaning all odours from the pelts was not practical in the time frame of the experiments. It is unlikely that neonates left a significant odour trail behind them as they climbed since there was no evidence from traces derived from the video recordings of successive young following the path of the young before them. The movements of the young were watched continuously and recorded with a video camera. Young were kept moist using a fine saline spray. At the end of the experiment the pouch young were placed back in their mother's pouch.

The path that the newborn took was drawn by placing a transparent sheet over a screen projecting the video. A dot was made for the position of the newborn (between the young's scapulae) every $10 \mathrm{~s}$ and the sequential dots connected by a line. An area of $1 \mathrm{~cm}$ around each swab was marked on the transparent sheet and a swab was considered 'chosen' when a newborn spent $30 \mathrm{~s}$ with its nose within $1 \mathrm{~cm}$ of that swab. The result of the first trial in which a pouch young made a choice was counted for the results. Three of the 23 pouch young became stuck in the dry pelt at the starting point and so were not included in the data analysis. Data were analysed using a one-tailed binomial test ( $R$, version 2.5.1; http://www.R-project.org/).

\section{Declaration of interest}

The authors declare that there is no conflict of interest that could be perceived as prejudicing the impartiality of the research reported.

\section{Funding}

This work was supported by the Holsworth Wildlife Research Endowment awarded to Nanette $Y$ Schneider and through an Australian Research Council Federation Fellowship awarded to Marilyn B Renfree.

\section{Acknowledgements}

We thank Joan Clark, Bruce Abaloz, Kerry Martin and Scott Brownless for assistance with electron microscopy, histology and animal handling respectively and the wallaby research group for help with the animals.

\section{References}

Ashwell KW, Marotte LR \& Cheng G 2008 Development of the olfactory system in a wallaby (Macropus eugenii). Brain, Behavior and Evolution 71 216-230.

Berghard A \& Buck LB 1996 Sensory transduction in vomeronasal neurons: evidence for G alpha o, G alpha i2, and adenylyl cyclase II as major components of a pheromone signalling cascade. Journal of Neuroscience 16 909-918.

Cannon JR, Bakker HR, Bradshaw SD \& McDonald IR 1976 Gravity as the sole navigational aid to the newborn quokka. Nature 25942.

Coppola DM, Budde J \& Millar L 1993 The vomeronasal duct has a protracted postnatal development in the mouse. Journal of Morphology 218 59-64.

Erhardt H \& Meinel W 1979 Electron microscope observations of the olfactory epithelium of the hedgehog, Erinaceus europaeus Linnaeus, 1758 (Insectivora, Erinaceidae). Zoologisches Jahrbuch der Anatomie $101113-121$.

Estes R 1972 The role of the vomeronasal organ in mammalian reproduction. Mammalia 36 315-341.

Farbman AI \& Menco BP 1986 Development of olfactory epithelium in the rat. In Ontogeny of Olfaction, pp 45-56. Ed. W Breipohl. Berlin: Springer-Verlag.

Garrosa M, Iniguez C, Fernandez JM \& Gayoso MJ 1992 Developmental stages of the vomeronasal organ in the rat: a light and electron microscopic study. Journal für Hirnforschung 33 123-132.

Garrosa M, Gayoso MJ \& Esteban FJ 1998 Prenatal development of the mammalian vomeronasal organ. Microscopy Research and Technique 41 456-470.

Gemmell RT \& Nelson J 1988 The ultrastructure of the olfactory system of three newborn marsupials species. Anatomical Record 221 655-662.

Gemmell RT \& Rose RW 1989 The senses involved in movement of newborn Macropodoidea and other marsupials from cloaca to pouch. In Kangaroos, Wallabies and Rat-Kangaroos, pp 349-354. Eds G Grigg, P Jarman \& I Hume. New South Wales, Australia: Surrey Beatty \& Sons Pty Limited.

Gemmell RT \& Selwood L 1994 Structural development in the newborn marsupial, the stripe-faced dunnart, Sminthopsis macroura. Acta Anatomica 149 1-12. 
Gemmell RT, Peters B \& Nelson J 1988 Ultrastructure identification of Merkel cells around the mouth of newborn marsupials. Anatomy and Embryology 177 403-408.

Gesteland RC, Yancey RA \& Farbman AI 1982 Development of olfactory receptor neuron selectivity in the rat fetus. Neuroscience 7 3127-3136.

Graves BM \& Duvall D 1983 A role for aggregation pheromones in the evolution of mammal like reptile lactation. American Naturalist 122 835-839.

Halpern M \& Martinez-Marcos A 2003 Structure and function of the vomeronasal system: an update. Progress in Neurobiology 70 245-318.

Hill JP \& Hill WCO 1955 The growth stages of the native cat (Dasyurus viverrinus) together with observations on the anatomy of the newborn young. Transactions of the Zoological Society of London 28 349-452.

Hudson R \& Distel H 1983 Nipple location by newborn rabbits: evidence for pheromonal guidance. Behaviour 81 260-275.

Hudson R \& Distel H 1986 Pheromonal release of suckling in rabbits does not depend on the vomeronasal organ. Physiology \& Behavior 37 123-128.

Hughes RL \& Hall LS 1984 Embryonic development in the common brushtail possum Trichosurus vulpecula. In Possums and Gliders, pp 197-212. Eds AP Smith \& ID Hume. Sydney: Australian Mammal Society.

Hughes RL, Hall LS, Tyndale-Biscoe CH \& Hinds LA 1989 Evolutionary implication of macropodid organogenesis. In Kangaroos, Wallabies and Rat-Kangaroos, pp 377-405. Eds G Grigg, P Jarman \& I Hume. New South Wales, Australia: Surrey Beatty \& Sons Pty Limited.

Jia C, Goldmann G \& Halpern M 1997 Development of vomeronasal receptor neuron subclasses and establishment of topographic projections to the accessory olfactory bulb. Developmental Brain Research 102 209-216.

Jones TE \& Munger BL 1985 Early differentiation of the afferent nervous system in glabrous snout skin of the opossum (Monodelphis domesticus). Somatosensory Research 3 169-184.

Kovach JK \& Kling A 1967 Mechanisms of neonate sucking behaviour in the kitten. Animal Behaviour 15 91-101.

Krieger J, Schmitt A, Lobell D, Gudermann T, Schultz G, Breer H \& Borkhoff I 1999 Selective activation of G protein subtypes in the vomeronasal organ upon stimulation with urine derivates. Journal of Biological Chemistry 274 4655-4662.

Lin PJ, Phelix C \& Krause WJ 1988 An immunohistochemical study of olfactory epithelium in the opossum before and after birth. Zeitschrift für Mikroskopisch-Anatomische Forschung 102 272-282.

Matsuoka M, Yoshida-Matsuoka J, Iwasaki N, Norita M, Costanzo RM \& Ichikawa M 2001 Immunocytochemical study of G(i)2alpha and $\mathrm{G}(\mathrm{o}) \mathrm{alpha}$ on the epithelium surface of the rat vomeronasal organ. Chemical Senses 26 161-166.

McCluskey SU, Marotte LR \& Ashwell KW 2008 Development of the vestibular apparatus and central vestibular connections in a wallaby (Macropus eugenii). Brain, Behavior and Evolution 71 271-286.

McCrady E 1938 The Embryology of the Opossum, Philadelphia: Wister Institute Press.

Mykytowycz R \& Ward M 1971 Some reaction of nestlings of wild rabbit, Oryctolagus cuniculus, when exposed to natural rabbit odors. Forma et Functio 4 137-148.
National Health and Medical Research Council 2004 Australian Code of Practice for the Care and Use of Animals for Scientific Purposes. Canberra ACT: Australian Government.

Pedersen P \& Blass E 1982 Prenatal and postnatal determinants of the first suckling episode in the albino rat. Developmental Psychobiology 15 349-356.

Renfree MB \& Tyndale-Biscoe CH 1978 Manipulation of marsupial embryos and pouch young. In Methods in Mammalian Reproduction, pp 307-331. Ed. JC Daniel. New York: Academic Press.

Renfree MB, Fletcher TP, Blanden DR, Lewis PR, Shaw G, Gordon K, Short RV, Parer-Cook E \& Parer D 1989 Physiological and behavioural events around the time of birth in macropodid marsupials. In Kangaroos, Wallabies and Rat-Kangaroos, pp 323-337. Eds G Grigg, P Jarman \& I Hume. New South Wales, Australia: Surrey Beatty, Sons Pty.

Salazar I \& Sanchez Quinteiro P 1998 Supporting tissue and vasculature of the mammalian vomeronasal organ: the rat as a model. Microscopy Research and Technique 41 492-505.

Schaal B, Coureaud G, Langlois D, Ginies C, Semon E \& Perrier G 2003 Chemical and behavioural characterization of the rabbit mammary pheromone. Nature 424 68-72.

Schneider NY, Fletcher TP, Shaw G \& Renfree MB 2008 The vomeronasal organ of the tammar wallaby. Journal of Anatomy 213 93-105.

Stickrod G, Kimble D \& Smotherman W 1982 In utero taste/odour aversion conditioning in the rat. Physiology \& Behavior 28 5-7.

Taniguchi K 2008 Embryonic and postnatal differentiation of olfactory epithelium and vomeronasal organ in the Syrian hamster. Journal of Veterinary Medical Science 70 57-64.

Teicher MH \& Blass E 1977 First suckling response of the newborn albino rat: the roles of olfaction and amniotic fluid. Science 4317 635-636.

Teicher MH, Stewart WB, Kauer JS \& Shepherd GM 1980 Suckling pheromone stimulation of a modified glomerular region in the developing rat olfactory bulb revealed by the 2-deoxyglucose method. Brain Research 194 530-535.

Tirindelli R, Mucignat-Caretta C \& Ryba NJP 1998 Molecular aspects of pheromonal communication via the vomeronasal organ of mammals. Trends in Neurosciences 21 482-486.

Tyndale-Biscoe CH \& Renfree MB 1987 Reproductive Physiology of Marsupials, Cambridge, UK: Cambridge University Press.

Wöhrmann-Repenning A \& Barth-Müller U 1994 Functional anatomy of the vomeronasal complex in the embryonic development of the pig. Acta Theriologica 39 313-323.

Worley PF, Baraban JM, Van Dop C, Neer EJ \& Snyder SH 1986 Go, a guanine nucleotide-binding protein: immunohistochemical localization in rat brain resembles distribution of second messenger systems. PNAS 83 4561-4565.

Received 17 April 2009

First decision 13 May 2009

Revised manuscript received 30 June 2009

Accepted 28 July 2009 